\title{
Preparation and Characterization of Geopolymer Cement
}

\author{
Essam A. Kishar ${ }^{\text {a }}$, Said A. Sayed ${ }^{\text {b }}$, Bahaa A. Salah ${ }^{\text {b }}$ and Mostafa M. Abdullah ${ }^{\text {b }}$ \\ ${ }^{a}$ Chemistry Department, Faculty of Women for Arts, Science, and Education, Ain shams University. \\ ${ }^{\mathrm{b}}$ Chemistry Department, Faculty of Science, Helwan University
}

\begin{abstract}
Effect of some artificial pozzolana such as ground granulate blast furnace slag (GGBFS), cement kiln by-pass dust (CKD), silica fume (SF), and fly ash (FA) on geopolymer composition and its resistance to sulphate attack was studied. Various mixes are prepared using different liquid/solid ratios (L/S) by weight. Sodium hydroxide pellets (SH) and commercial sodium silicate liquid (SSL) are used as an activator which was dissolved in the mixing water. The hydration characteristics of the different mixes have been tested via determination of bulk density, total porosity, combined water, compressive strength, and XRD analysis at different time intervals from 1 up to 180 days in water. The results show that the combined water content of the alkali-activated GBFS pastes gradually increases up to 180 days in all mixes. The bulk density increases and the total porosity decreases, as a result of addition of the pozzolanic materials. The compressive strength also increases up to 180 days. All mixes showed good stability of its compressive strength values in $5 \% \mathrm{MgSO}_{4}$ solution. The data show that SF1 (85\% GGBFS+15\% SF) activated by (0.5 mol/kg SSL, and $2.5 \mathrm{M} \mathrm{SH})$, and S3 (100\% GGBFS) activated by $(0.5 \mathrm{~mol} / \mathrm{kg} \mathrm{SSL}$, and $2.5 \mathrm{M} \mathrm{SH})$ are the most appropriate binding materials (geopolymer cement) that have good different properties so that they can be used as alternative binding materials to the ordinary Portland cement.
\end{abstract}

Keywords: Artificial pozzolana, slag, cement kiln by-pass dust, silica fume, fly ash, geopolymer, and sodium silicate.

\section{Introduction:}

It is now accepted that new binders are needed to replace ordinary Portland cement (OPC) for enhanced environmental and durability performance. These binders are still at the early stage of development and, hence, need further research work in order to become technically and economically viable construction materials [Pacheco-Torgal et al., 2012]. Geopolymer cements are a group of alkali activated materials exhibiting superior engineering properties compared to OPC. The molecular structure of geopolymer consists of an aluminosilicate network. The simplest aluminosilicate network of this type is called polysialate which is the abbreviation of silicon-oxo-aluminate. In fact, geopolymers are products of the chemical reactions between aluminosilicate and alkali polysialate in a relatively highly alkaline medium. The resulting products, i.e., geopolymer cements, usually exhibit better engineering properties such as compressive strength and resistance against aggressive media, compared to Portland cements [Allahverdi et al., 2008].

Corresponding author: Mostafa Mohamed Abdullah Afifi

E-mail: mostafa_mm53@yahoo.com 
Pozzolanas are materials containing reactive silica and/ or alumina which, on their own have little or no binding property, but when mixed with lime in the presence of water, will set and harden like cement. They are important ingredients in the production of alternative cementing material to OPC. Pozzolanas can be divided into two groups: natural pozzolana such as volcanic ash and diatomite, and artificial pozzolana such as calcined clay, pulverized fuel ash, and ash from burnt agricultural waste. Many plant ashes have high silica content and are therefore suitable as a pozzolana [Pontes et al., 2013] and [Tsado et al., 2014].

Blast furnace slag is produced from the manufacture of pig iron. In the process of reducing iron ore to iron, a molten slag forms as a nonmetallic liquid that floats on top of the molten iron. The molten slag is then separated from the liquid metal and cooled. Depending on the cooling method, three types of slag are produced, namely air cooled, expanded, and granulated. If the molten slag is quenched sufficiently rapidly by water, the ground product is known as ground granulated blast furnace slag (GGBFS) [Li, Sun et al., 2010] Slag was the first cementitious materials to be activated by alkali and due to its latent hydraulic properties, the ground granulated blast-furnace slag (GGBS) becomes the most suitable material for alkali activated cement. According to [Adam, 2009]. Cement kiln dust (CKD) is a by-product of cement manufacturing, cement kiln dust is a fine powdery material similar in appearance to OPC. It is composed of micron- sized particles collected from electrostatic precipitators during the production of cement clinker [Mann et al., 2009].

The production of 1 ton cement requires about 2.8 ton raw materials (including fuels and other materials), 5 to $10 \%$ of these materials are dust out of the dryers, mills, kilns, coolers and transportation facilities [Cement, 2012]. Silica fume (SF) is a byproduct of the smelting process in the silicon and ferrosilicon industry. The reduction of high-purity quartz to silicon at temperatures up to $2,000^{\circ} \mathrm{C}$ produces $\mathrm{SiO}_{2}$ vapor, which is oxidized and condense in the low temperature zone to tiny particles consisting of non-crystalline silica [Chandra \& Berntsson, 2002].

Addition of silica fume to concrete improves the durability of concrete and also protects the embedded steel from corrosion. When fine pozzolana particles are dispersed in the paste, they generate a large number of nucleation sites for the precipitation of the hydration products. Therefore, this mechanism makes the paste more homogeneous and dense as for the distribution of the fine pores. This is due to the reaction between the amorphous silica of the pozzolanic and the calcium hydroxide produced by the cement hydration reactions [Ho, 1997]. Fly ash particles are typically spherical, finer than Portland cement and lime, ranging in diameter from less than $1 \mu \mathrm{m}$ to no more than $150 \mu \mathrm{m}$. Fly ash is defined as 'the finely divided residue that results from the combustion of ground or powdered coal and that is transported by flue gasses from the combustion zone to the particle removal system [Hardjito \& Rangan, 2005]. An important achievement in the use of fly ash in concrete is the development of high volume fly ash (HVFA) concrete that successfully replaces the use of OPC in concrete up to $60 \%$ and yet possesses excellent mechanical properties with enhanced durability performance. 
HVFA concrete has been proved to be more durable and resource-efficient than the OPC concrete. The HVFA technology has been put into practice, for example the construction of roads in India, which implemented 50\% OPC replacement by the fly ash [Hardjito \& Rangan, $2005 \&$ Motorwala et al., 2013].

\section{Materials and Method}

\subsection{Materials and specimens}

The materials used in this investigation were ground granulate blast furnace slag (GGBFS), cement kiln by-pass dust (CKD), silica fume (SF), fly ash (FA), sodium hydroxide pellets $(\mathrm{SH})$, and commercial sodium silicate liquid (SSL). The chemical compositions of the used materials are given in Table (1).

Table (1): Chemical composition of the starting materials, (mass \%)

\begin{tabular}{|c|c|c|c|c|}
\hline $\begin{array}{c}\text { Materials } \\
\text { Constituents }\end{array}$ & Slag & $\begin{array}{c}\text { Silica } \\
\text { fume }\end{array}$ & Fly ash & $\begin{array}{c}\text { Cement } \\
\text { Kiln dust }\end{array}$ \\
\hline $\mathbf{S i O}_{\mathbf{2}}$ & 34.10 & 92.20 & 63.20 & 14.16 \\
\hline $\mathbf{A l}_{2} \mathbf{O}_{\mathbf{3}}$ & 12.40 & 2.50 & 26.34 & 3.98 \\
\hline $\mathbf{F e}_{2} \mathbf{O}_{3}$ & 0.77 & 2.80 & 5.10 & 3.42 \\
\hline $\mathbf{C a O}$ & 42.30 & 0.49 & 2.20 & 53.87 \\
\hline $\mathbf{M g O}$ & 6.50 & 0.40 & 0.10 & 0.86 \\
\hline $\mathbf{S O}_{3}$ & 0.90 & 0.15 & 0.15 & 3.68 \\
\hline $\mathbf{K}_{2} \mathbf{O}$ & 0.35 & 0.40 & 0.76 & 6.62 \\
\hline $\mathbf{N a}_{2} \mathbf{O}$ & 0.26 & 0.20 & 0.44 & 3.01 \\
\hline $\mathbf{C l}^{-}$ & 0.08 & 0.00 & 0.00 & 7.43 \\
\hline $\mathbf{L . O . I}$ & 1.50 & 2.14 & 2.30 & 2.80 \\
\hline $\mathbf{T o t a l}^{-}$ & 99.08 & 101.28 & 100.59 & 99.83 \\
\hline
\end{tabular}




\subsection{Procedure}

Different mixes were prepared as shown in Table (2). Sodium hydroxide pellets (SH) and commercial sodium silicate liquid (SSL) were used as an activator dissolved in the mixing water. The pastes were mixed in automatic mixer for 2 minutes. The pastes were molded in the form of one cubic inch cube molds [Khater, 2013], and jolted well by the jolting table. The geopolymer pastes were cured at about $100 \%$ relative humidity at room temperature for 1 day in the incubator. The hardened pastes are then removed from the molds after attaining the final setting and cured under water for different time intervals up to 180 days. Some cubes were immersed (after 7 days curing in $\mathrm{H}_{2} \mathrm{O}$ ) in $5 \% \mathrm{MgSO}_{4}$ solution for different time intervals up to 180 days.

Table (2): Mix composition, water/solid (W/S) ratio and designations.

\begin{tabular}{|c|c|c|c|c|c|c|c|c|}
\hline No. & $\begin{array}{c}\text { Mix } \\
\text { Abb. }\end{array}$ & $\begin{array}{c}\text { GGBFS, } \\
\text { Wt. \% }\end{array}$ & $\begin{array}{c}\text { CKD, } \\
\text { Wt. } \\
\mathbf{\%}\end{array}$ & $\begin{array}{c}\text { SF, } \\
\text { Wt. } \\
\mathbf{\%}\end{array}$ & $\begin{array}{c}\text { FA, } \\
\text { Wt. } \\
\text { \% }\end{array}$ & $\begin{array}{c}\text { SSL } \\
\text { Conc. } \\
(\mathbf{m o l} / \mathbf{K g})\end{array}$ & $\begin{array}{c}\text { SH } \\
\text { Conc. } \\
\text { (M) }\end{array}$ & $\begin{array}{c}\text { W/S } \\
\text { Ratio } \\
(\%)\end{array}$ \\
\hline $\mathbf{1}$ & S 1 & 100 & - & - & - & 0.5 & 0.25 & 28.6 \\
\hline $\mathbf{2}$ & S 2 & 100 & - & - & - & 0.5 & 1.5 & 28.8 \\
\hline $\mathbf{3}$ & S 3 & 100 & - & - & - & 0.5 & 2.5 & 28.6 \\
\hline $\mathbf{4}$ & S 4 & 100 & - & - & - & 0.5 & 4.0 & 29.0 \\
\hline $\mathbf{5}$ & SF 1 & 85 & - & - & 15 & 0.5 & 2.5 & 28.0 \\
\hline $\mathbf{6}$ & SF 2 & 95 & - & - & 5 & 0.5 & 2.5 & 26.2 \\
\hline $\mathbf{7}$ & SS 1 & 85 & - & 15 & - & 0.5 & 2.5 & 28.6 \\
\hline $\mathbf{8}$ & SS 2 & 95 & - & 5 & - & 0.5 & 2.5 & 26.2 \\
\hline $\mathbf{9}$ & SD 1 & 95 & 5 & - & - & 0.5 & 2.5 & 30.0 \\
\hline $\mathbf{1 0}$ & SD 2 & 90 & 10 & - & - & 0.5 & 2.5 & 35.0 \\
\hline
\end{tabular}

\subsection{Methods of investigation}

The hydration characteristics of the different geopolymer mixes were investigated via;

1. Determination of bulk density, total porosity, and combined water content.

2. Compressive strength measurements using compression and bend test plant ToniPRAX according to EN-ISO 4012 with load measuring range 3 to $300 \mathrm{KN}$.

3. X-ray diffraction analysis to identify the hydration products formed at different ages of the different mixes using ARL X'TRA X-ray diffractmeter. 


\section{Results and Discussion:}

\subsection{Combined water content (Wn \%)}

Chemically combined water contents $(\mathrm{Wn})$ for all mixes cured in water and $5 \% \mathrm{MgSO}_{4}$ up to 180 days are represented in Table (3a) and (3b) respectively. The Wn content can be adopted as a criterion to evaluate the relative amount of hydration products and the relative hydration degrees between different samples with the same kind of hydration products. It is clear that the combined water content of the alkali-activated GBFS pastes (S1-SD2) gradually increases up to 180 days in water as shown in Table (3a). This may be due to the continuous hydration and accumulation of hydrated products, which are deposited in the available open pores.

The Wn content of mix $\mathrm{S} 1$ at the age of 2 days in $\mathrm{H}_{2} \mathrm{O}$ is $5.1 \%$, but at mix $\mathrm{S} 4$ at the same age reaches $6.2 \%$, indicating that the degree of hydrolytic destruction of alkali activated GBFS increases with the content of $\mathrm{Na}_{2} \mathrm{O}$. Table (3a) indicates that the influence of increasing alkalinity on the hydration of GBFS increases with age. At the age of 180 days, Wn contents of the mixes S1, S2, S3, and S4 are $8.7 \%, 9.5 \%, 10.1 \%$, and $10.4 \%$ respectively. i.e., the hydration time increases, the amount of hydration products increases. Hence the chemically combined water content increases, which may be mainly due to the highest hydraulic properties of GBFS with increasing the alkaline concentration. So S4 shows the highest value of the chemically combined water of all mixes due to the highest concentration of the activator. In the aggressive solution $\left(5 \% \mathrm{MgSO}_{4}\right)$ also, the combined water content of the alkali activated GBFS pastes gradually increases up to 180 days in all mixes as shown in Table (3b). The same occurs by addition of cement kiln by-pass dust (CKD), silica fume (SF), fly ash (FA) due to the continuous hydration and accumulation of the hydrated products.

Table (3a): Chemically combined water content (Wn \%) for all mixes cured up to 180 days cured in water

\begin{tabular}{|c|c|c|c|c|c|}
\hline Days & $2 d$ & $7 \mathrm{~d}$ & $28 \mathrm{~d}$ & $90 \mathrm{~d}$ & $180 \mathrm{~d}$ \\
\hline Mix & \multicolumn{5}{|c|}{ Wn \% } \\
\hline S 1 & 5.1 & 5.3 & 6.8 & 7.8 & 8.7 \\
\hline S 2 & 5.3 & 5.4 & 6.9 & 7.9 & 9.5 \\
\hline S 3 & 6.0 & 6.2 & 7.1 & 8.1 & 10.1 \\
\hline S 4 & 6.2 & 6.4 & 7.5 & 8.3 & 10.4 \\
\hline SF 1 & 6.4 & 7.2 & 8.4 & 12.5 & 13.2 \\
\hline SF 2 & 6.6 & 6.9 & 7.9 & 10.9 & 11.1 \\
\hline SS 1 & 5.9 & 6.2 & 6.9 & 13.4 & 14.1 \\
\hline SS 2 & 5.8 & 7.1 & 8.1 & 11.2 & 12.1 \\
\hline SD 1 & 7.5 & 7.9 & 13.2 & 14.5 & 14.9 \\
\hline SD 2 & 6.9 & 7.7 & 9.1 & 9.2 & 9.4 \\
\hline
\end{tabular}


Table (3b): Chemically combined water content (Wn \%) for all mixes cured up to 180 days cured in $5 \% \mathrm{MgSO}_{4}$ solution.

\begin{tabular}{|c|c|c|c|c|c|}
\hline \multirow{2}{*}{ Mix } & $2 d$ & $7 \mathrm{~d}$ & $28 \mathrm{~d}$ & $90 \mathrm{~d}$ & $180 \mathrm{~d}$ \\
\hline & \multicolumn{5}{|c|}{ Wn \% } \\
\hline S 1 & 5.5 & 5.9 & 6.2 & 7.3 & 8.4 \\
\hline S 2 & 5.9 & 6.2 & 7.2 & 8.5 & 10.5 \\
\hline S 3 & 6.3 & 6.4 & 8.2 & 9.5 & 11.1 \\
\hline S 4 & 7.1 & 8.1 & 8.3 & 9.1 & 11.2 \\
\hline SF 1 & 7.2 & 7.5 & 7.9 & 10.7 & 11.8 \\
\hline SF 2 & 6.6 & 7.2 & 7.7 & 11.2 & 12.1 \\
\hline SS 1 & 7.1 & 7.2 & 7.4 & 8.8 & 10.2 \\
\hline SS 2 & 5.4 & 5.6 & 5.7 & 6.1 & 8.2 \\
\hline SD 1 & 7.5 & 7.8 & 8.3 & 8.5 & 10.4 \\
\hline SD 2 & 8.1 & 8.5 & 9.4 & 11.4 & 11.8 \\
\hline
\end{tabular}

\subsection{Compressive strength}

The compressive strength of hardened alkali-activated GBFS cured in water and $5 \%$ $\mathrm{MgSO}_{4}$ up to 180 days are represented in table (4a), and (4b) respectively. The compressive strength of all mixes increases with curing time. However Mix S3 shows the highest values of compressive strength at most of curing ages of hydration. As the amount of alkali activator increases up to $2.5 \mathrm{M}$ the compressive strength increases. It is clear that the values of the compressive strength are related to formation of more hydration products, which may be due to accelerate the activation process. Further increase in $\mathrm{Na}_{2} \mathrm{O}$ content (than $2.5 \mathrm{M}$ ) results in a decrease of compressive strength. One plausible reason is that increasing of $\mathrm{Na} 2 \mathrm{O}$ content in the activating solution may result in reduced level of long-range structural ordering products [Duxson et al., 2007].

Utilization of cement kiln dust (CKD) with its high alkali content in the activation of geopolymer specimens to create nonconventional cementitious binders, mixes SD1, and SD2 show that 5\% CKD is the optimum ratio for geopolymer formation as shown in Table (4a). The activation of GGPFS by $2.5 \mathrm{M} \mathrm{NaOH}$ along with 5\% CKD results in a best enhancement in mechanical characteristics. This specimens exhibit high resistance to sulfate attack as there are little deterioration up to 180 days of immersing in $5 \% \mathrm{MgSO}_{4}$ solution. Adding silica fume to GBFS in Mixes SS1, and SS2 shows that Silica fume addition up to 5\% greatly enhances the geopolymerization process with the formation of a well-refined and compact matrix, where silica fume represents an enrichment source of amorphous silica and enhancing geopolymerization [Ho, 1997]. However further increase of SF content to $15 \%$ in mix SS2 leads to decrease in the mechanical characteristics of the reaction product. This specimens exhibit high resistance to sulfate attack as shown in Table (4b). 
Table (4a): Compressive strength for all mixes cured up to 180 days in water.

\begin{tabular}{|c|c|c|c|c|c|}
\hline \multirow{2}{*}{ Mix Days } & 2 d & 7 d & 28 d & 90 d & 180 d \\
\cline { 2 - 6 } & \multicolumn{5}{|c|}{ Compressive strength } \\
\hline S 1 & 70 & 302 & 530 & 700 & 835 \\
\hline S 2 & 556 & 664 & 720 & 792 & 920 \\
\hline S 3 & 560 & 752 & 862 & 945 & 980 \\
\hline S 4 & 593 & 620 & 716 & 820 & 910 \\
\hline SF 1 & 640 & 662 & 720 & 900 & 940 \\
\hline SF 2 & 580 & 684 & 861 & 950 & 775 \\
\hline SS 1 & 512 & 586 & 660 & 692 & 770 \\
\hline SS 2 & 581 & 680 & 750 & 880 & 891 \\
\hline SD 1 & 520 & 665 & 688 & 850 & 876 \\
\hline SD 2 & 410 & 460 & 500 & 503 & 505 \\
\hline
\end{tabular}

Table (4b): Compressive strength for all mixes cured up to 180 days in $5 \% \mathrm{MgSO}_{4}$ solution.

\begin{tabular}{|c|c|c|c|c|c|}
\hline \multirow{2}{*}{ Mix Days } & 2 d & 7 d & 28 d & 90 d & 180 d \\
\cline { 2 - 6 } & \multicolumn{5}{|c|}{ Compressive strength } \\
\hline S 1 & 365 & 503 & 612 & 740 & 760 \\
\hline S 2 & 640 & 688 & 774 & 826 & 905 \\
\hline S 3 & 796 & 813 & 840 & 880 & 930 \\
\hline S 4 & 650 & 780 & 808 & 838 & 900 \\
\hline SF 1 & 672 & 680 & 692 & 740 & 820 \\
\hline SF 2 & 615 & 660 & 704 & 712 & 715 \\
\hline SS 1 & 598 & 610 & 640 & 700 & 620 \\
\hline SS 2 & 624 & 670 & 700 & 750 & 830 \\
\hline SD 1 & 520 & 665 & 688 & 850 & 876 \\
\hline SD 2 & 410 & 460 & 500 & 503 & 505 \\
\hline
\end{tabular}

\subsection{Bulk density}

The bulk densities of hardened activated GBFS cured up to 180 days in water and $5 \%$ $\mathrm{MgSO}_{4}$ are represented in table (5a), and (5b) respectively. It is clear that the bulk density increases with curing time up to 180 days in all mixes. The bulk density of alkali-activated GBFS increases with curing time due to the continuous activation and formation of hydration products. Which may deposit in the open pores that increase the bulk density of the activated slag, this increasing of alkali activator enhances the bulk density of the investigated pastes. The alkali activator enhance the production of higher concentration of $\left[\mathrm{SiO}_{4}\right]^{-4}$ which increases the rate of hydration and formation of more C-S-H as shown in Figure (1) [Heikal et al., 2014]. As the amount of alkali activator content increases, the bulk density accordingly increases. Also in the aggressive solution $\left(5 \% \mathrm{MgSO}_{4}\right)$ the resistance towards sulphate attack solution increases with the increase of alkali-activated content as indicated by the stability of the compressive strength values as shown in Table (4b). This may be mainly due to the increase of bulk density which hinders the penetration of sulphate ions in the matrix. 
Table (5a): Bulk density for all mixes cured up to 180 days in water.

\begin{tabular}{|c|c|c|c|c|c|}
\hline \multirow{2}{*}{ Mix Days } & 2 d & 7 d & 28 d & 90 d & 180 d \\
\cline { 2 - 6 } & \multicolumn{5}{|c|}{ Bulk density } \\
\hline S 1 & 2.15 & 2.19 & 2.19 & 2.22 & 2.24 \\
\hline S 2 & 2.19 & 2.22 & 2.23 & 2.23 & 2.24 \\
\hline S 3 & 2.19 & 2.23 & 2.24 & 2.33 & 2.34 \\
\hline S 4 & 2.21 & 2.22 & 2.23 & 2.31 & 2.33 \\
\hline SF 1 & 2.11 & 2.11 & 2.17 & 2.18 & 2.18 \\
\hline SF 2 & 2.18 & 2.18 & 2.18 & 2.19 & 2.15 \\
\hline SS 1 & 2.12 & 2.14 & 2.15 & 2.15 & 2.18 \\
\hline SS 2 & 2.21 & 2.21 & 2.21 & 2.21 & 2.24 \\
\hline SD 1 & 2.16 & 2.16 & 2.17 & 2.18 & 2.21 \\
\hline SD 2 & 2.08 & 2.09 & 2.09 & 2.09 & 2.12 \\
\hline
\end{tabular}

Table (5b): Bulk density for all mixes cured up to 180 days in $5 \% \mathrm{MgSO}_{4}$ solution.

\begin{tabular}{|c|c|c|c|c|c|}
\hline \multirow{2}{*}{ Mix } & $2 \mathrm{~d}$ & $7 \mathrm{~d}$ & $28 \mathrm{~d}$ & $90 \mathrm{~d}$ & $180 \mathrm{~d}$ \\
\hline & \multicolumn{5}{|c|}{ Bulk density } \\
\hline S 1 & 2.21 & 2.23 & 2.23 & 2.31 & 2.32 \\
\hline S 2 & 2.23 & 2.22 & 2.31 & 2.34 & 2.35 \\
\hline S 3 & 2.34 & 2.34 & 2.34 & 2.38 & 2.39 \\
\hline S 4 & 2.23 & 2.34 & 2.34 & 2.35 & 2.34 \\
\hline SF 1 & 2.12 & 2.12 & 2.14 & 2.15 & 2.16 \\
\hline SF 2 & 2.18 & 2.18 & 2.19 & 2.19 & 2.21 \\
\hline SS 1 & 2.12 & 2.13 & 2.13 & 2.14 & 2.12 \\
\hline SS 2 & 2.18 & 2.19 & 2.22 & 2.22 & 2.23 \\
\hline SD 1 & 2.16 & 2.16 & 2.15 & 2.14 & 2.13 \\
\hline SD 2 & 2.08 & 2.09 & 2.11 & 2.08 & 2.05 \\
\hline
\end{tabular}

\subsection{Total porosity}

The total porosity for alkaline activated GBFS for all mixes cured up to 180 days in water and $5 \% \mathrm{MgSO}_{4}$ are represented in table (6a), and (6b) respectively. As the alkaline activation of GBFS increases, more hydration products are formed, which precipitate in some available open pores leading to decrease the total porosity. The addition of $4 \mathrm{M}$ of $\mathrm{Na}_{2} \mathrm{O}$ (mix S4) gives the lower values of total porosity. The sharp decrease in the total porosity values of mix S4 was shown from 90 to 180 days of hydration. On the other side, the decrease in the total porosity values occurred after 7 days for mixes S1, S2, S3, and S4 may be mainly due to the increase of the content of alkaline activator, which may accelerates the activation of GBFS forming more hydration products, which fill a part of the available pore volume of the paste; therefore the total porosity decreases. The total porosity values are in a good agreement with compressive strength values, such that as the total porosity decreases the compressive strength increase. Also in the aggressive solution $\left(5 \% \mathrm{MgSO}_{4}\right)$ the resistance towards sulphate attack solution increases with the increase of alkali activated contents as indicated by the stability of the compressive strength values as shown in Table (4b). This is mainly due to the decrease of the total porosity which hinders the penetration of sulphate ions in the matrix. 
Table (6a): Total porosity for all mixes cured up to 180 days in water.

\begin{tabular}{|c|c|c|c|c|c|}
\hline \multirow{2}{*}{ Mix Days } & 2 d & 7 d & 28 d & 90 d & 180 d \\
\cline { 2 - 6 } & \multicolumn{5}{|c|}{ Total porosity } \\
\hline S 1 & 36.5 & 36.4 & 31.9 & 29.6 & 26.9 \\
\hline S 2 & 35.9 & 35.2 & 31.9 & 29.1 & 25.8 \\
\hline S 3 & 33.4 & 33.6 & 34.1 & 29.1 & 26.3 \\
\hline S 4 & 33.3 & 32.2 & 29.5 & 28.4 & 21.9 \\
\hline SF 1 & 35.1 & 33.7 & 31.5 & 25.8 & 22.6 \\
\hline SF 2 & 34.5 & 34.3 & 32.5 & 27.8 & 27.1 \\
\hline SS 1 & 35.4 & 34.6 & 32.3 & 22.3 & 20.5 \\
\hline SS 2 & 36.1 & 33.3 & 31.8 & 27.5 & 25.4 \\
\hline SD 1 & 34.3 & 33.4 & 25.9 & 23.1 & 21.9 \\
\hline SD 2 & 35.5 & 34.2 & 32.3 & 31.8 & 32.1 \\
\hline
\end{tabular}

Table (6b): Total porosity for all mixes cured up to 180 days in $5 \% \mathrm{MgSO}_{4}$ solution.

\begin{tabular}{|c|c|c|c|c|c|}
\hline \multirow{2}{*}{ Mix } & $2 \mathrm{~d}$ & $7 d$ & $28 \mathrm{~d}$ & $90 \mathrm{~d}$ & $180 \mathrm{~d}$ \\
\hline & \multicolumn{5}{|c|}{ Total porosity } \\
\hline S 1 & 36.5 & 35.5 & 34.4 & 32.7 & 30.7 \\
\hline S 2 & 35.9 & 35.1 & 35.1 & 30.9 & 27.4 \\
\hline S 3 & 35.9 & 35.2 & 32.2 & 29.3 & 26.7 \\
\hline S 4 & 32.1 & 31.8 & 31.3 & 29.9 & 24.4 \\
\hline SF 1 & 34.1 & 33.2 & 32.1 & 28.6 & 23.6 \\
\hline SF 2 & 34.1 & 33.4 & 32.1 & 27.5 & 25.3 \\
\hline SS 1 & 33.9 & 34.6 & 32.3 & 29.4 & 26.1 \\
\hline SS 2 & 36.5 & 36.2 & 35.7 & 34.2 & 28.8 \\
\hline SD 1 & 34.3 & 33.5 & 32.2 & 30.8 & 27.2 \\
\hline SD 2 & 33.5 & 32.3 & 31.1 & 28.3 & 26.8 \\
\hline
\end{tabular}

\subsection{Phase composition}

XRD patterns of alkali activated GBFS samples are shown in Figs. (1) to (5). It can be seen that the peak represents $\mathrm{C}-\mathrm{S}-\mathrm{H}$ phase at $3.02 \mathrm{~A}^{\circ}$ changes in the period of curing time at 2 to 28 days, suggesting that poor crystalline C-S-H gel may be produced in the pastes. Indeed, once GBFS powder is mixed with the alkaline solution, geopolymer gel and C-S-H gel could be formed after setting and hardening. The geopolymer exhibits increase in the mechanical properties as represented in Table (4a). For all XRD diagrams, broad and diffuse peaks are shown around $\mathrm{d}=2.28-3.36 \mathrm{~A}^{\circ}$, implying amorphous or short-ordering structure phases generally present in alkali-activated GBFS. In alkali activated GBFS, the presence of the strong peak at $\mathrm{d}=3.02 \mathrm{~A}^{\circ}$ is attributed to $\mathrm{C}-\mathrm{S}-\mathrm{H}$ phases, which are composed of calcium silicate hydrate. The compressive strength is in a good agreement with XRD analysis. 


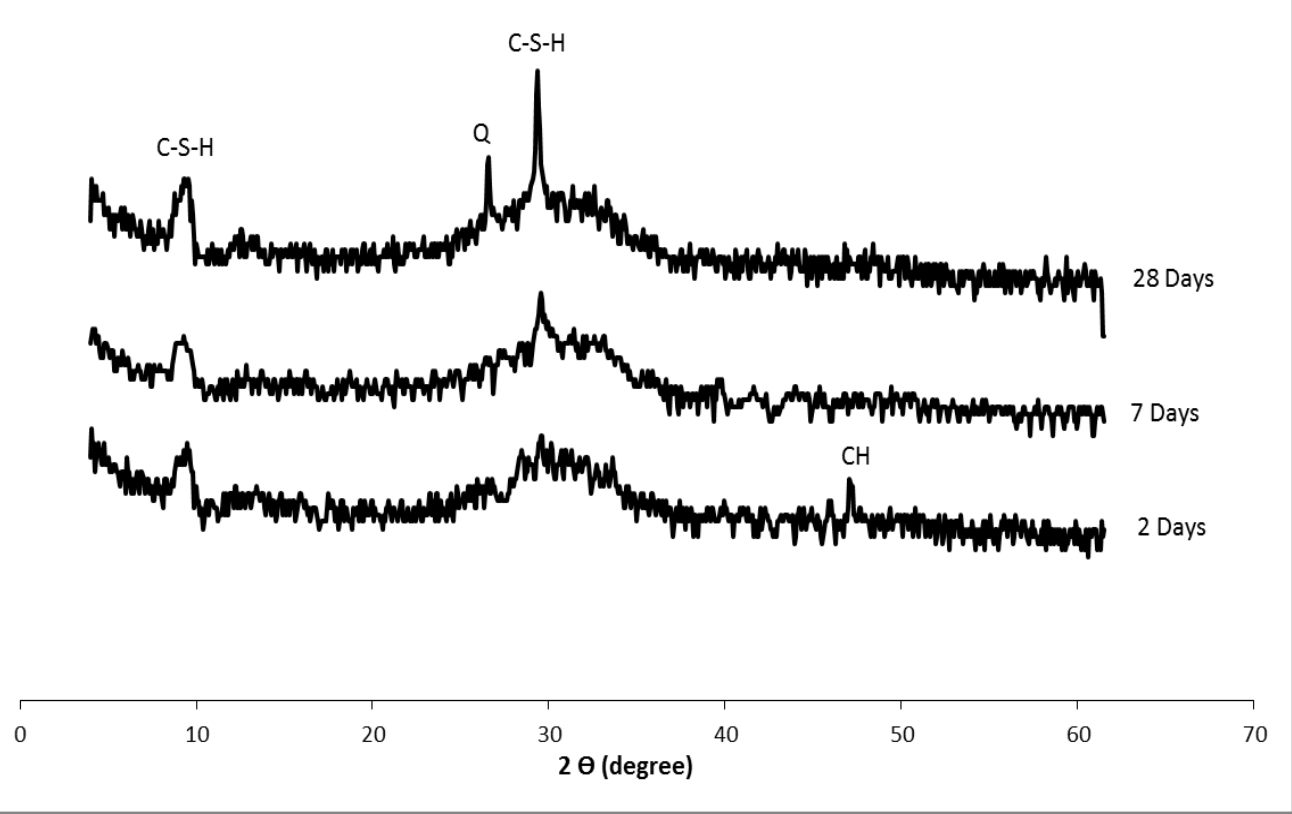

Figure (1): X-ray diffraction patterns for mix $100 \%$ GBFS (S 1) which show the presence of C-S-H (Calcium silicate hydrate), Q (Quartz), and $\mathrm{CH}\left(\mathrm{Ca}(\mathrm{OH})_{2}\right)$ phases formed during the hydration reaction.

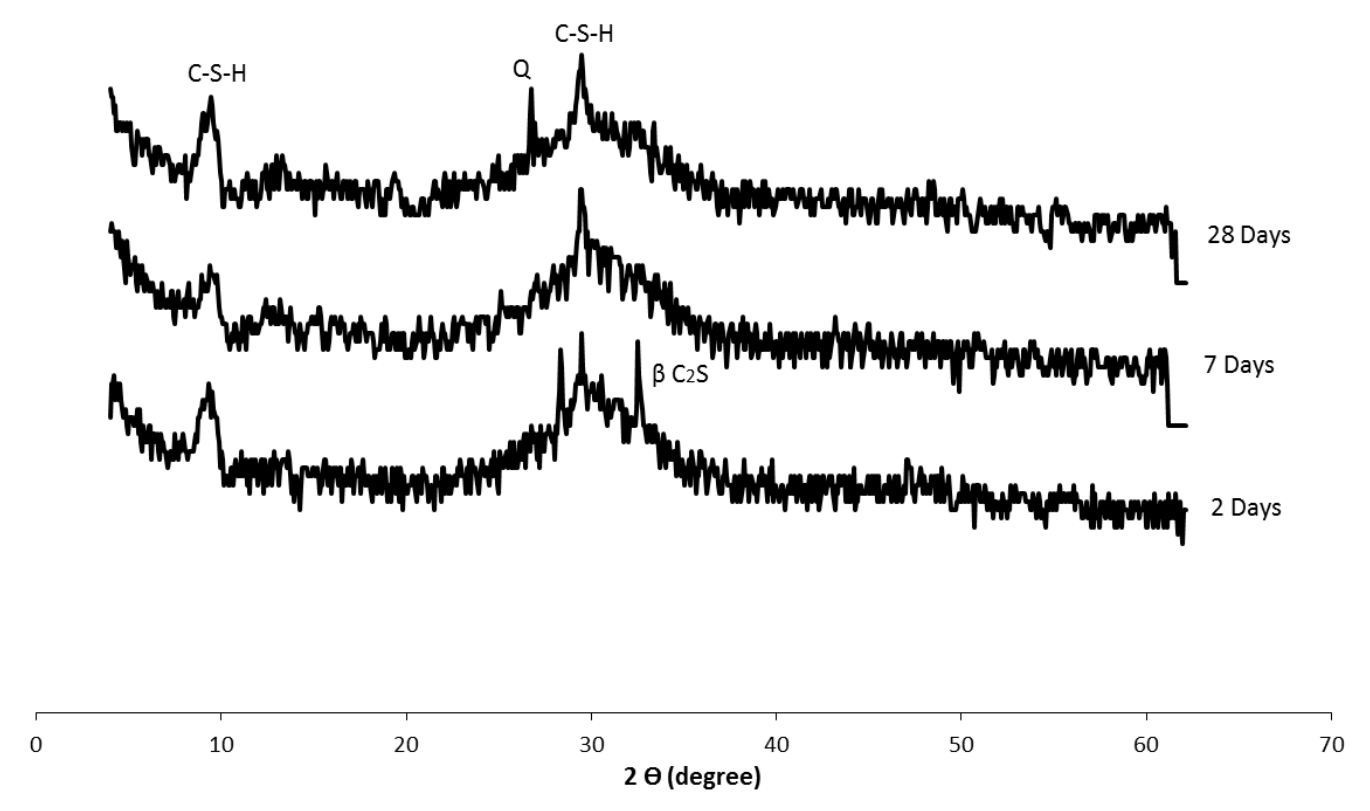

Figure (2): X-ray diffraction patterns for mix $100 \%$ GBFS (S 3) which show the presence of $\mathrm{C}-\mathrm{S}-\mathrm{H}$ (Calcium silicate hydrate), $\mathrm{Q}$ (Quartz), and $\beta \mathrm{C}_{2} \mathrm{~S}$ (Di calcium silicate) phases formed during the hydration reaction. 


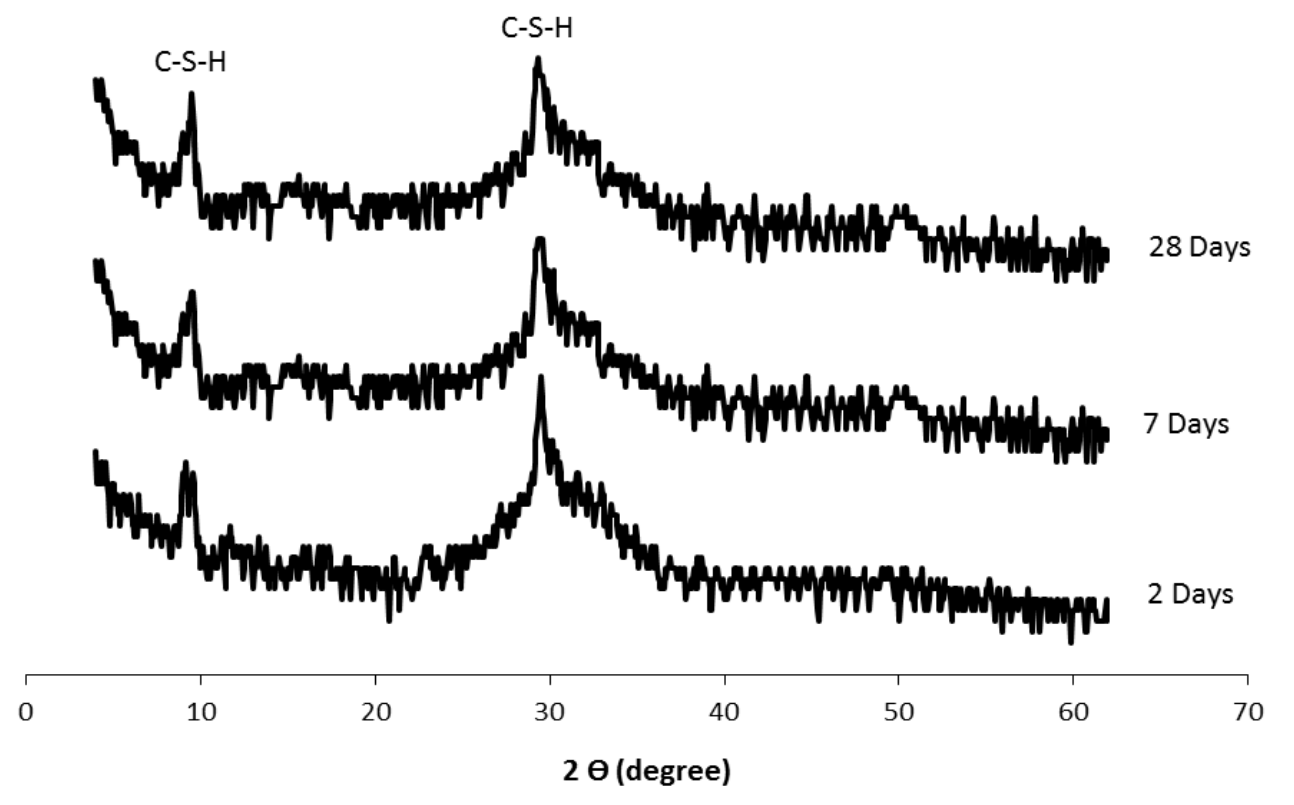

Figure (3): X-ray diffraction patterns for mix (SD1), which show the presence of $\mathrm{C}-\mathrm{S}-\mathrm{H}$ (Calcium silicate hydrate) phase formed during the hydration reaction.

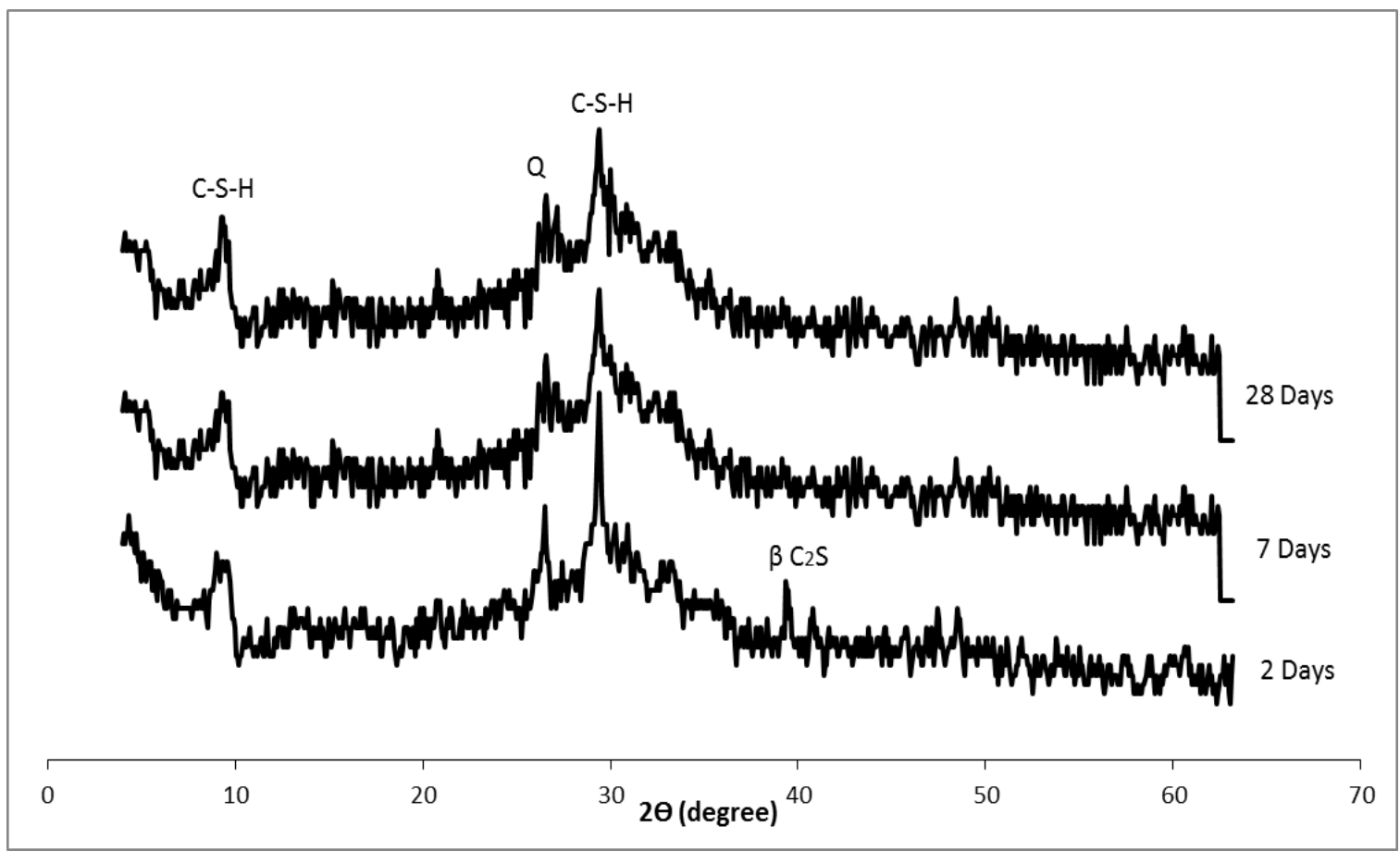

Figure (4): X-ray diffraction patterns for mix (SF 1). Which show the presence of C-S-H (Calcium silicate hydrate), Q (Quartz), and $\beta \mathrm{C}_{2} \mathrm{~S}$ (Di calcium silicate) phases formed during the hydration reaction. 


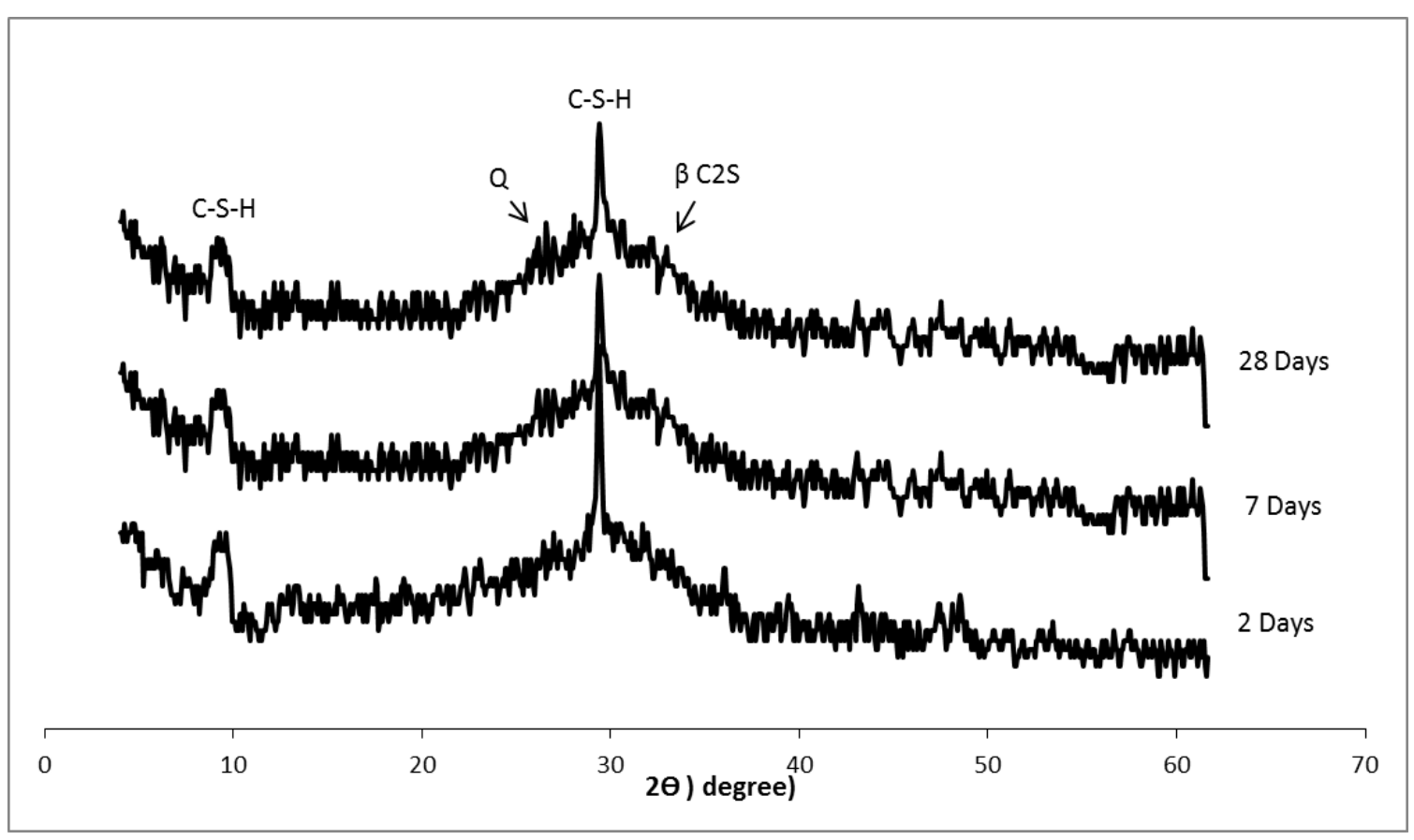

Figure (5): X-ray diffraction patterns for mix (SS 1), which show the presence of C-S-H (Calcium silicate hydrate), Q (Quartz), and $\beta \mathrm{C}_{2} \mathrm{~S}$ (Di calcium silicate) phases formed during the hydration reaction.

\subsection{Resistance to magnesium sulphate solution}

Magnesium sulphate causes distress into concrete decreasing $\mathrm{OH}^{-}$concentration; C-S-H phase may be decomposed and caused losses in compressive strength [Heikal et al., 2014]. The compressive strength of alkali-activated GBFS immersed (after 7 days curing in $\mathrm{H}_{2} \mathrm{O}$ ) in $5 \% \mathrm{MgSO}_{4}$ solution up to 180 days was studied. The data show that the compressive strength of alkaline-activated slag increases with curing time as the hydration progresses up to 180 days as represented in Table (4b). The compressive strength of mixes S3, SF1, SS2, and SD1 shows the highest values, due to a good pozzolanic activity in alkaline activation that exhibits high resistance to sulphate medium up to 180 days.

Addition of silica fume to GBFS improves the durability of the geopolymer cement, such that when fine pozzolana particles are dispersed in the paste, they generate a large number of nucleation sites for the precipitation of the hydration products. Therefore, this mechanism makes the paste more homogeneous and dense as for the distribution of the fine pores. Addition of fly ash to GBFS also improves the mechanical properties; the activated fly ash is particularly durable and highly resistant to aggressive solutions like $5 \% \mathrm{MgSO}_{4}$. Unlike that the compressive strength of OPC increases up to 28 days then decrease gradually due to the formation of expanding and softening ettringite hydrated products [Heikal et al., 2014]. Alkali-activated GBFS improves the durability and the resistance to chemical attack. By comparing the alkali-activated slag with OPC, it is found that the strength of alkali activated slag increases up to 180 days, due to the formation of additionally hydration products, without the formation of expanding and softening ettringite hydrated products. 
The resistance towards sulphate attack solution increases with the increase of alkaliactivated contents. This may be mainly due to the decrease of the total porosity which hinders the penetration of sulphate ions in the matrix, this can be attributed to the fact that the alkali activated GBFS do not have free lime content in its matrix and geopolymers themselves are not easily attacked by aggressive medium containing sulphate ions.

\section{Conclusions}

- All mixes show good stability of its compressive strength values in $5 \% \mathrm{MgSO}_{4}$ solution. This is believed to be due to a good pozzolanic activity in alkalineactivation that exhibits higher resistance to sulphate medium up to 180 days. The immersion of alkali activated GBFS pastes in $5 \% \mathrm{MgSO}_{4}$ solution enhances the activation of GBFS pastes [Duxson et al., 2007].

- Using 5\% CKD is the optimum ratio for the geopolymer formation and activation of GGBFS by $2.5 \mathrm{M} \mathrm{NaOH}$, SD1 exhibit high resistance to sulfate attack up to 180 days of immersing in $5 \% \mathrm{MgSO}_{4}$ solution.

- Silica fume addition up to $5 \%$ greatly enhances the geopolymerization process with the formation of a well-refined and compact matrix, as silica fume represents an enrichment source of amorphous silica and enhancing geopolymerization. While increase of SF content to $15 \%$ in SS1 leads to the decrease in the mechanical characteristics of the reaction product.

- The data show that SF1 (85\% GGBFS+15\% SF) activated by $(0.5 \mathrm{~mol} / \mathrm{kg} \mathrm{SSL}$, and $2.5 \mathrm{M} \mathrm{SH}$ ), and S3 (100\% GGBFS) activated by (0.5 mol/kg SSL, and 2.5 $\mathrm{M} \mathrm{SH}$ ) are the most appropriate binding materials (geopolymer cement) that have good different properties that can be used as alternative binding material to the ordinary Portland cement. 


\section{References}

Adam, A. "Strength and durability properties of alkali activated slag and fly ash-based geopolymer concrete". Journal of Environmental and Chemical Engineering, 202. (2009).

Allahverdi, A., Mehrpour, K., \& Kani, E. N. "Taftan Pozzolan-Based Geopolymer Cement". International Journal of Engineering Science, 19(3), 1-5. (2008).

Cement, F. "The characterization and the utilization of cement kiln dust (CKD) as partial replacement of Portland cement in mortar and concrete production". Journal of natural sciences, 53. (2012).

Chandra, S., \& Berntsson, L. "Supplementary Cementing Materials. Lightweight Aggregate Concrete", 67 - 90, (2002).

Duxson, P., Fernández-Jiménez, A., Provis, J. L., Lukey, G. C., Palomo, A., \& Van Deventer, J. S. J.. "Geopolymer technology: The current state of the art". Journal of Materials Science, 42(9), 2917-2933 (2007).

Hardjito, D., \& Rangan, B. V. "Development and properties of low-calcium fly ashbased geopolymer concrete". Research Report GC, 94. (2005).

Heikal, M., Nassar, M. Y., El-Sayed, G., \& Ibrahim, S. M. "Physico-chemical, mechanical, microstructure and durability characteristics of alkali activated Egyptian slag". Construction and Building Materials, 69, 60-72. (2014).

Ho, C. "Influence of Silica Fume on Concrete. Journal of mechanical and civil Engineering", 44-47. (2014).

Khater, H. M. "Effect of silica fume on the characterization of the geopolymer materials". International Journal of Advanced Structural Engineering, 5(1), 12. (2013).

Li, C., Sun, H., \& Li, L. A review: "The comparison between alkali-activated slag (Si + $\mathrm{Ca})$ and metakaolin $(\mathrm{Si}+\mathrm{Al})$ cements". Cement and Concrete Research, 40(9), 13411349. (2010).

Mann, A., Ibrahim, K., Oyewale, A. O., Amupitan, J. O., I, J., Polytechnic, T. F. Medicine, T. "Utilization of cement kiln dust in industry cement bricks". Research Paper. Geosystem Engineering, 29-34. (2011).

Motorwala, A., Shah, V., Kammula, R., Nannapaneni, P., \& Raijiwala, P. D. B. "Alkali Activated Fly Ash Based Geopolymer Concrete". International Journal of Emerging technology and advanced engineering, 3(1), 159-166. (2013).

Pacheco-Torgal, F., Abdollahnejad, Z., Camões, a. F., Jamshidi, M., \& Ding, Y. "Durability of alkali-activated binders: A clear advantage over Portland cement or an unproven issue?" Construction and Building Materials, 30, 400-405. (2012)

Pontes, J., Silva, A S., \& Faria, P.. "Evaluation of pozzolanic reactivity of artificial pozzolans". Materials Science Forum, 730-732, 433-438. (2013)

Tsado, T. Y., Yewa, M., \& Yaman, S.. "Comparative Analysis of Properties of Some Artificial Pozzolana in Concrete Production". International Journal of Engineering and technology, 4(5), 251-255. (2014) 


\section{الملذص باللغة العربية \\ تحضير وتوصيف الاسمنت الجيوبوليمر}

عصام عبدالعزيز كيشار 1 ، سعيد انور سيد2 ، بهاء احمد صلاح 2، مصطفي محمد عبداله عفيفي 2.

1. قسم الكيمياء، كلية البنات للاداب و العلوم و التربية، جامعه عين شمس .

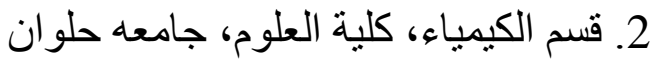

تم دراسة تأثير بعض انواع من البوزو لانا الصناعية مثل حبيبات خبث الحديد ، غبار الاسمنت، دخان

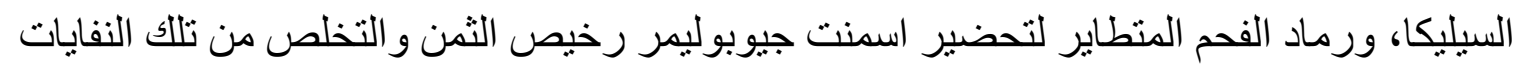

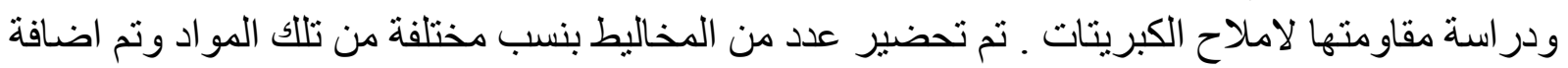

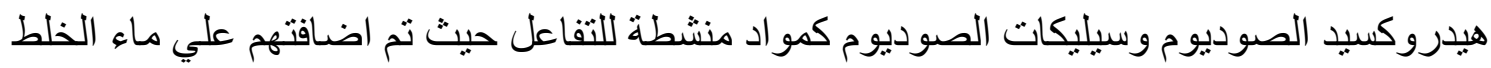

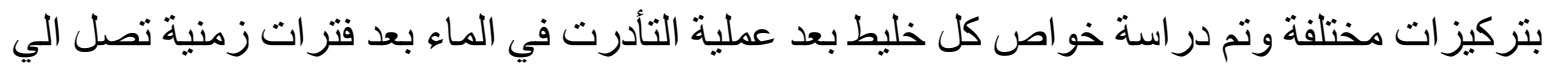

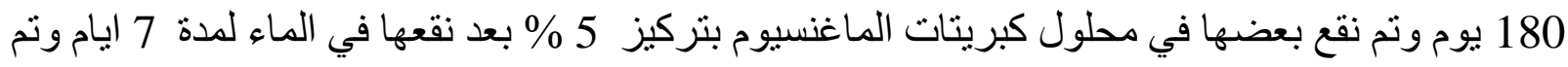

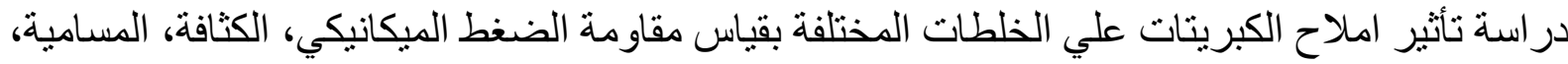

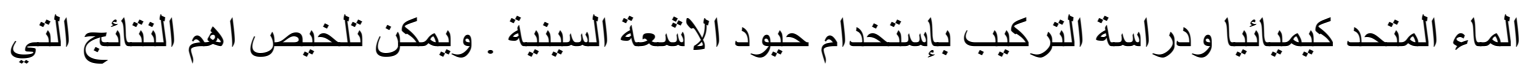
حصلنا عليها فيما يلي:

أظهرت جميع المخاليط مقاومة ضغط ميكانيكي جيد وثبات بعد نقعها في محلول كبريتات الماغنسيوم

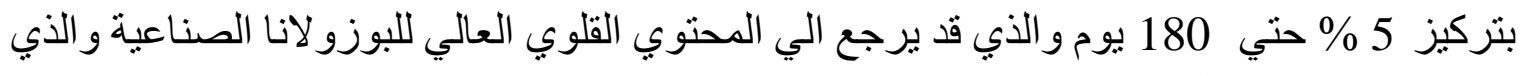
يعتقد انه ينشط التفاعل ويكسبه مقاومة ضغط ميكانيكي عالي.

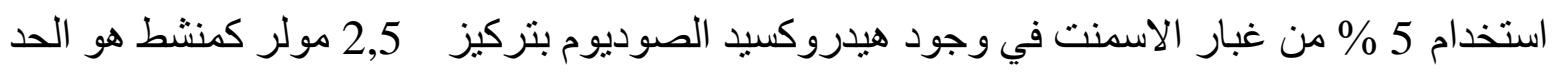

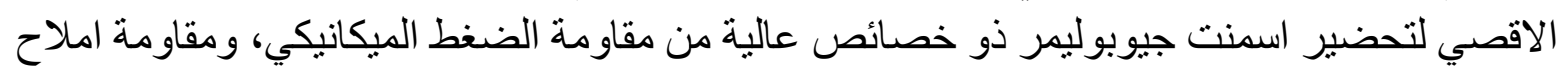

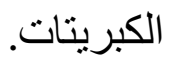

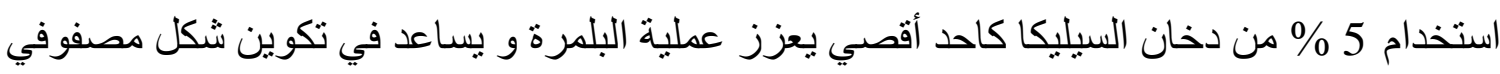

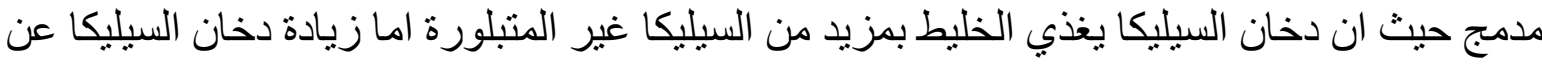

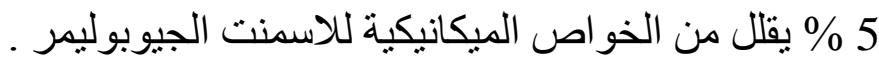

مكعبات الاسمنت الجيوبوليمر التي تم تحضر ها بإستخدام رماد الفحم المتطاير في وجود هيدروكسيد

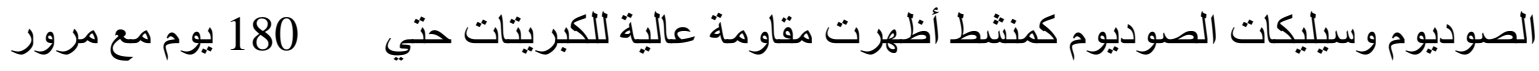

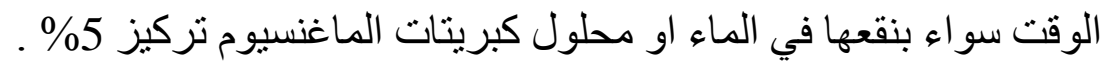

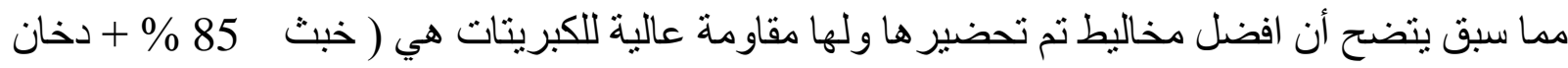
السيليكا 15 \%) و ( خبث 100 \% ) في وجود منشط بتركيز ( هيدروكسيد الصوديوم 


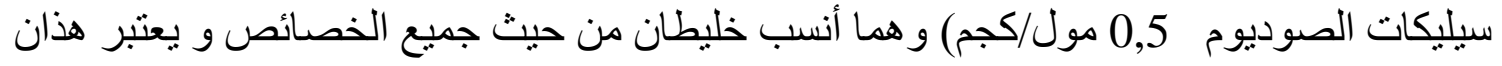

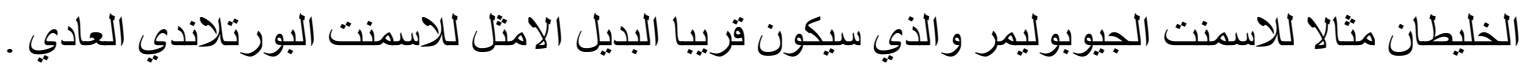

